\title{
Survival Analysis of Antineoplastic Treatment for Older Patients with Metastatic Non-Small-Cell Lung Cancer: A Clinical Database Study
}

This article was published in the following Dove Press journal: Cancer Management and Research

\author{
Chin-Hsiu $\mathrm{Yu}^{\prime}$ \\ Ya-Ai Cheng ${ }^{2}$ \\ Ru-Yih Chen (iD $^{3}$ \\ Yu-Lung $\mathrm{Wu}^{4}$ \\ Min-Hsi Lin ${ }^{5}$ \\ 'Department of Information Engineering, \\ I-Shou University, Kaohsiung, Taiwan; \\ ${ }^{2}$ Department of Healthcare \\ Administration, I-Shou University, \\ Kaohsiung, Taiwan; ${ }^{3}$ Department of \\ Family Medicine, Kaohsiung Veterans \\ General Hospital, Kaohsiung, Taiwan; \\ ${ }^{4}$ Department of Information \\ Management, I-Shou University, \\ Kaohsiung, Taiwan; ${ }^{5}$ Division of Chest \\ Medicine, Kaohsiung Veterans General \\ Hospital, Kaohsiung, Taiwan
}

Correspondence: Ru-Yih Chen

Department of Family Medicine,

Kaohsiung Veterans General Hospital,

No. 386, Dazhong Ist Road, Zuoying

District, Kaohsiung City 8134I4, Taiwan

(R.O.C.)

Tel +886-7-346-8236

Fax +886-7-342-2288

Email louie0812@gmail.com
Purpose: To explore whether antineoplastic treatment can improve overall survival (OS) in older patients with metastatic non-small-cell lung cancer (mNSCLC).

Patients and Methods: Using the cancer registry database of a tertiary medical center in Taiwan, we followed patients 65 years old and above with pathologically proved mNSCLC. Chi-square test and Cox regression were used to analyze differences in clinical characteristics, the treatments they received, and factors predicting survival. Kaplan-Meier survival analysis was used to analyze OS differences.

Results: A total of 542 older patients were diagnosed with mNSCLC from 2011 to 2017. Multivariate Cox regression showed that patients receiving targeted therapy (TT) alone, chemotherapy (CT) alone, and crossover (CO) treatment were at significantly less risk of short OS [hazard ratio (HR) $0.351,95 \%$ confidence interval (CI), 0.257-0.479; HR 0.517, CI 0.376-0.711; and HR 0.544, CI 0.373-0.792, respectively]. Patients at significantly increased risk of short OS were those aged $\geq 85$ years and those assigned poorer Eastern Cooperative Oncology Group Performance Status (ECOG-PS) scores (HR 1.513, CI 1.135-2.017, and HR 2.854, CI 2.188-3.724, respectively). The result of Kaplan-Meier survival analysis of 418 patients with ECOG-PS scores 0-2 suggested that patients who received antineoplastic treatments had a significantly better median OS than those receiving supportive care (SC), those receiving TT having the best result (SC, 4.00 months; TT, 21.17 months; CT, 12.83 months; CO, 15.83 months, $\mathrm{P}<0.001)$.

Conclusion: Antineoplastic treatments, especially TT, can improve OS for selected older patients with mNSCLC.

Keywords: chemotherapy, targeted therapy, crossover treatment, stage IV lung cancer, older patient, survival

\section{Introduction}

With a worldwide increase in aging, there will be a substantial increase in the number of older persons who will undoubtedly be diagnosed with and die of cancer. ${ }^{1}$ In the United States, lung cancer is responsible for most deaths due to cancer. Lung cancer is mainly found in people aged 65 years and older. Although a small number of people are diagnosed with this disease below the age of 45 years, the average age at the time of diagnosis is about $70 .^{2,3}$ Thus, there is a great need for information on how age-related health problems affect cancer prevention, detection, prognosis, and treatment. In Taiwan, more than $14 \%$ of the population was 65 years and older in 2018 and this proportion is expected to exceed $20 \%$ by 
2026. Cancer has been the leading cause of death in Taiwan since 1984. About $25 \%$ of people in this age group died of cancer in 2019, mostly cancers of the trachea, bronchus, and lung. ${ }^{4}$

Older adults are more likely to be diagnosed with nonsmall-cell lung cancer at later stages and have lower 5 -year survival rates for this disease. ${ }^{2}$ When faced with this catastrophic illness, these patients will often need help financially and help to perform daily activities. ${ }^{5,6}$ Their age, health status, and possible deterioration in cognition may reduce their ability to perform physical activities, understand the course and outcome of antineoplastic treatment, and manage the possible side effects of antineoplastic treatments. ${ }^{7-9}$ All of this comes with the increased psychological burden and poorer quality of life for them and their family. ${ }^{10,11}$ Thus, older advanced cancer patients may refuse antineoplastic treatment to reduce this burden. $^{12}$

Recent developments in antineoplastic treatment have not only reduced the side effects of conventional chemotherapies, but they have also improved the treatment outcomes of patients with advanced-stage disease. ${ }^{13}$ Studies have suggested that some targeted therapy agents might be good first-line drugs against lung cancer. ${ }^{14}$ However, most of these studies have been clinical trials of carefully selected patients and assessment of effectiveness has been based on progression-free survival (PFS), not overall survival (OS). Few studies have investigated OS in older patients treated for metastatic non-small-cell lung cancer (mNSCLC) in the real world. Therefore, using data extracted from one hospital clinical database, we explored whether antineoplastic treatment improved OS in older patients with mNSCLC, a population sometimes reluctant to undergo what they perceive as unnecessary or futile aggressive treatment.

\section{Patients and Methods \\ Cancer Registry Center Database}

In Taiwan, hospitals with greater than 50-bed capacities providing outpatient and hospitalized cancer care are required to digitally register clinical data of all newly diagnosed malignant neoplasms in their respective hospital's cancer registry. At least once a year, the hospitals follow up on their patient's survival status by assessing medical records, telephone inquiries, or checking Taiwan's Cancer Registry (TCR). In case of death, the hospitals calculate OS from the initial diagnosis of cancer to the date of death and record it in their own registry. The patients found to be still alive at the end of the follow-up period were "censored".

The hospitals' registries are submitted once a year to TCR, which keeps track of the incidences of various cancers throughout Taiwan. This registry maintains a database containing the details of various cancer research efforts and performs periodic checks identifying possible duplications in patients, mistakes, and inconsistencies in the data. Taiwan's National Public Health Association has been contracted to supervise the registry and organize an advisory board to standardize definitions of terminology, coding, and procedures of the registry's reporting system. ${ }^{15}$

\section{Study Design}

In Sep. 2019, we used the cancer registry of a tertiary medical center in southern Taiwan to collect data on pathologically proved mNSCLC in patients aged 65 years old and above diagnosed from January 1, 2011, to December 31, 2017. Metastatic NSCLC (mNSCLC) was defined as nonsmall cell lung cancer with distant metastasis, that is, stage IVa or IVb according to the 7th American Joint Committee on Cancer and the International Union for Cancer Control Tumor-node-metastasis Cancer Staging system.

We collected clinical data, including gender, age, smoking behavior, and physician-assigned Eastern Cooperative Oncology Group Performance Status (ECOGPS) scores in the hospital cancer registry, as well as relevant neoplasm-related variables, including histomorphology, pleural effusion, and the treatment modalities received. Patients were divided into those receiving supportive care (SC) and those receiving chemotherapy (CT) alone, targeted therapy (TT) alone, or crossover (CO) treatment, meaning the patients received chemotherapy and targeted therapy at different times. Taiwan's National Health Insurance began paying for immune checkpoint inhibitors in April 2019. Before that date, the hospital's standard lung cancer treatment guidelines did not include this modality and no patient in this database received this therapy. This study was approved by the institutional review board of Veterans General Hospital Kaohsiung, approval number VGHKS19-CT8-12.

\section{Statistical Analyses}

Relevant data, which were provided by the hospital in Office Excel 2013 form, were imported into IBM SPSS version 20.0 for sorting and statistical analysis. Data were first analyzed descriptively and deductively using chi- 
square test ( $\chi 2$ test) and Cox regression analysis. Median OS differences for patients were analyzed using KaplanMeier (KM) survival analysis and Log-rank test. A p-value of less than 0.05 was considered significant.

\section{Results}

A total of 542 patients aged 65 and above (mean age 76.07 \pm 7.56 years) were diagnosed with $\mathrm{mNSCLC}$ and registered in the hospital's cancer registry between January 1, 2011, and December 31, 2017. Most patients (97.8\%) did not receive surgery targeting their primary cancer sites and no patient received radiotherapy as primary treatment. As can be seen in Table 1, despite their age, most of them (77.49\%) received antineoplastic therapy. There were significant differences between the treatment groups with regard to gender $(P<0.001)$, age $(P<0.001)$, smoking behavior $(P<0.001)$, ECOG-PS $(P<0.001)$, histomorphology $(P<0.001)$, and pleural effusion $(P=0.095)$.

Table 2 summarizes the results of our Cox regression analysis of OS. Multivariate Cox regression showed that patients receiving $\mathrm{TT}$ alone, $\mathrm{CT}$ alone, and $\mathrm{CO}$ treatment were at significantly less risk of short OS [hazard ratio (HR) $0.351,95 \%$ confidence interval (CI), 0.257-0.479; HR 0.517 , CI $0.376-0.711$; and HR 0.544 , CI $0.373-$ 0.792 , respectively]. Those aged $\geq 85$ years and those assigned poorer ECOG-PS scores (3-4) were at significantly higher risk of short OS (HR 1.513, CI 1.135-2.017, and HR 2.854, CI 2.188-3.724, respectively).

For the 418 patients with ECOG-PS 0-2, those receiving antineoplastic treatments had significantly better median OS than those receiving SC, and those receiving TT had the best OS (SC 4.00 months vs TT 21.17 months vs CT 12.83 months vs CO 15.83 months, $P<0.001$ ) (Figure $1 \mathrm{~A}$ ). For the 124 patients with ECOG-PS 3-4, those receiving TT and CT had longer survivals (3.07 and 5.13 months, respectively) than those receiving $\mathrm{SC}$ or $\mathrm{CO}$ (1.47 and 1.90 months, respectively) $(\mathrm{P}=0.002)$ (Figure $1 \mathrm{~B})$, though this result could be confounded by the small number of patients who received CT and $\mathrm{CO}$ treatment ( 7 and 6 patients, respectively) (Table 1). For three age groups (65-74,

Table I Baseline Characteristics of the Patients

\begin{tabular}{|c|c|c|c|c|c|c|}
\hline \multirow[t]{2}{*}{ Variables } & \multirow[t]{2}{*}{ Total (\%) } & \multicolumn{5}{|c|}{ Patient Number (\%) } \\
\hline & & sc & TT & CT & co & $P$ \\
\hline Patient number & $542(100)$ & $122(22.5 \mid)$ & $214(39.48)$ & $120(22.14)$ & $86(15.87)$ & \\
\hline $\begin{array}{l}\text { Sex } \\
\qquad \text { Male } \\
\text { Female }\end{array}$ & $\begin{array}{l}327(60.33) \\
215(39.67)\end{array}$ & $\begin{array}{l}90(16.61) \\
32(5.90)\end{array}$ & $\begin{array}{l}\text { I03 }(19.00) \\
\text { III }(20.48)\end{array}$ & $\begin{array}{l}83(15.31) \\
37(6.83)\end{array}$ & $\begin{array}{l}51(9.4 I) \\
35(6.46)\end{array}$ & $<0.001$ \\
\hline $\begin{array}{l}\text { Age (years) } \\
65-74 \\
75-84 \\
\geq 85\end{array}$ & $\begin{array}{l}257(47.42) \\
193(35.6 \mathrm{I}) \\
92(16.97)\end{array}$ & $\begin{array}{l}35(6.46) \\
43(7.93) \\
44(8.12)\end{array}$ & $\begin{array}{l}89(16.42) \\
92(16.97) \\
33(6.09)\end{array}$ & $\begin{array}{l}72(13.28) \\
37(6.83) \\
\mathrm{II}(2.03)\end{array}$ & $\begin{array}{l}61(11.25) \\
21(3.87) \\
4(0.74)\end{array}$ & $<0.001$ \\
\hline $\begin{array}{l}\text { Smoking }^{\mathrm{a}} \\
\text { No } \\
\text { Yes }\end{array}$ & $\begin{array}{l}305(56.27) \\
237(43.73)\end{array}$ & $\begin{array}{l}49(9.04) \\
73(13.47)\end{array}$ & $\begin{array}{l}149(27.49) \\
65(11.99)\end{array}$ & $\begin{array}{l}54(9.96) \\
66(12.18)\end{array}$ & $\begin{array}{l}53(9.78) \\
33(6.09)\end{array}$ & $<0.001$ \\
\hline $\begin{array}{l}\text { ECOG-PS } \\
\qquad \begin{array}{c}0-2 \\
3-4\end{array}\end{array}$ & $\begin{array}{l}418(77.12) \\
124(22.88)\end{array}$ & $\begin{array}{l}44(8.12) \\
78(14.39)\end{array}$ & $\begin{array}{l}|8|(33.40) \\
33(6.09)\end{array}$ & $\begin{array}{l}\text { II } 3(20.85) \\
7(1.29)\end{array}$ & $\begin{array}{l}80(14.76) \\
6(1.11)\end{array}$ & $<0.001$ \\
\hline $\begin{array}{l}\text { Histomorphology } \\
\text { Adenocarcinoma } \\
\text { Others }\end{array}$ & $\begin{array}{l}444(81.92) \\
98(18.08)\end{array}$ & $\begin{array}{l}75(13.84) \\
47(8.67)\end{array}$ & $\begin{array}{l}206(38.01) \\
8(1.48)\end{array}$ & $\begin{array}{l}82(15.13) \\
38(7.01)\end{array}$ & $\begin{array}{l}81(14.94) \\
5(0.92)\end{array}$ & $<0.001$ \\
\hline $\begin{array}{l}\text { Pleural Effusion } \\
\text { No } \\
\text { Yes }\end{array}$ & $\begin{array}{l}287(52.95) \\
255(47.05)\end{array}$ & $\begin{array}{l}60(11.07) \\
62(11.44)\end{array}$ & $\begin{array}{l}114(21.03) \\
100(18.45)\end{array}$ & $\begin{array}{l}74(13.65) \\
46(8.49)\end{array}$ & $\begin{array}{l}39(7.20) \\
47(8.67)\end{array}$ & 0.095 \\
\hline
\end{tabular}

Note: ${ }^{a}$ History of a former or current smoker.

Abbreviations: SC, supportive care; TT, targeted therapy; CT, chemotherapy; CO, crossover treatment; ECOG-PS, Eastern Cooperative Oncology Group Performance Status. 
Table 2 Cox Proportional Hazard Regression Model Analysis for All Patients ( $N=542)$

\begin{tabular}{|c|c|c|c|c|}
\hline \multirow[t]{2}{*}{ Variables } & \multicolumn{2}{|l|}{ Univariate Analysis } & \multicolumn{2}{|c|}{ Multivariate Analysis } \\
\hline & HR (95\% Cl) & $P$ & HR (95\% Cl) & $P$ \\
\hline \multicolumn{5}{|l|}{ Gender } \\
\hline Male. & I [Reference] & & I [Reference] & \\
\hline Female & $0.643(0.531-0.778)$ & $<0.001$ & $0.786(0.651-1.011)$ & 0.061 \\
\hline \multicolumn{5}{|l|}{ Age, years } \\
\hline $65-74$ & I [Reference] & & I [Reference] & \\
\hline $75-84$ & 1.405 (I.I44-I.725) & 0.001 & I.I85 (0.954-I.47I) & 0.125 \\
\hline$\geq 85$ & $2.185(1.689-2.826)$ & $<0.001$ & $1.513(1.135-2.017)$ & 0.005 \\
\hline \multicolumn{5}{|l|}{ Smoking $^{\mathrm{a}}$} \\
\hline No & I [Reference] & & I [Reference] & \\
\hline Yes & $1.666(1.383-2.008)$ & $<0.001$ & 1.161 (0.908-I.485) & 0.234 \\
\hline \multicolumn{5}{|l|}{ ECOG-PS } \\
\hline $0-2$ & I [Reference] & & I [Reference] & \\
\hline $3-4$ & $4.128(3.322-5.131)$ & $<0.001$ & $2.854(2.188-3.724)$ & $<0.001$ \\
\hline \multicolumn{5}{|l|}{ Histomorphology } \\
\hline Adenocarcinoma & I [Reference] & & I [Reference] & \\
\hline Others & $1.818(1.440-2.294)$ & $<0.001$ & $1.032(0.786-1.355)$ & 0.822 \\
\hline \multicolumn{5}{|l|}{ Pleural effusion } \\
\hline No & I [Reference] & & I [Reference] & \\
\hline Yes & $1.378(1.145-1.659)$ & 0.001 & $1.200(0.992-1.453)$ & 0.061 \\
\hline \multicolumn{5}{|l|}{ Treatment modalities } \\
\hline SC & I [Reference] & & I [Reference] & \\
\hline $\mathrm{TT}$ & $0.184(0.142-0.238)$ & $<0.001$ & 0.35 I (0.257-0.479) & $<0.001$ \\
\hline $\mathrm{CT}$ & $0.265(0.201-0.349)$ & $<0.001$ & $0.5 I 7(0.376-0.7 I I)$ & $<0.001$ \\
\hline $\mathrm{CO}$ & $0.249(0.184-0.336)$ & $<0.001$ & $0.544(0.373-0.792)$ & 0.002 \\
\hline
\end{tabular}

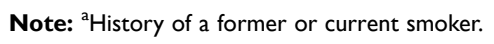

Abbreviations: HR, hazard ratio; Cl, confidence interval; ECOG-PS. Eastern Cooperative Oncology Group Performance Status; SC, supportive cancer; TT, targeted therapy; $\mathrm{CT}$, chemotherapy; $\mathrm{CO}$, crossover treatment.

75-84, and $\geq 85$ years), except for those aged $\geq 85$ years receiving $\mathrm{CO}$ treatment, those receiving antineoplastic treatment had significantly better OS than those receiving $\mathrm{SC}$ in all age groups (all $\mathrm{p}<0.001$ ). Those receiving $\mathrm{TT}$ alone had the best survival (Figure $2 \mathrm{~A}-\mathrm{C}$ ).

\section{Discussion}

Clinical trials have found that PFS of older patients with mNSCLC can be improved by systemic chemotherapy. However, the participants in most of these trials were carefully selected making selection bias more likely. ${ }^{16}$ While many Phase III studies have found patients receiving TT to have superior PFS and better side effect tolerance compared with chemotherapy, further follow-up studies have not found patients receiving TT to have better OS outcomes. Crossover treatment, a more aggressive approach, has been associated with shorter survival. ${ }^{17}$
Some studies wondering whether the results of clinical trials coincide with real-world results have called for more information on treatment outcomes so that older patients with advanced NSCLC can make treatment decisions based on personal life values. ${ }^{18,19}$ According to our study, patients with ECOG-PS 0-2 and age below 85 who received antineoplastic treatments have a significantly better OS and those who received TT have the best. Crossover treatment was not found to produce a better OS than TT or CT alone. Our findings were consistent with those reported by trials.

Taiwan has a national universal health insurance system that covers most of the costs of therapies for major injuries and catastrophic illnesses, including lung cancer. ${ }^{20}$ Therefore, most patients in Taiwan will not find the expense of medical treatment to be a reason for foregoing antineoplastic treatment. As can be seen in Table 1, most 

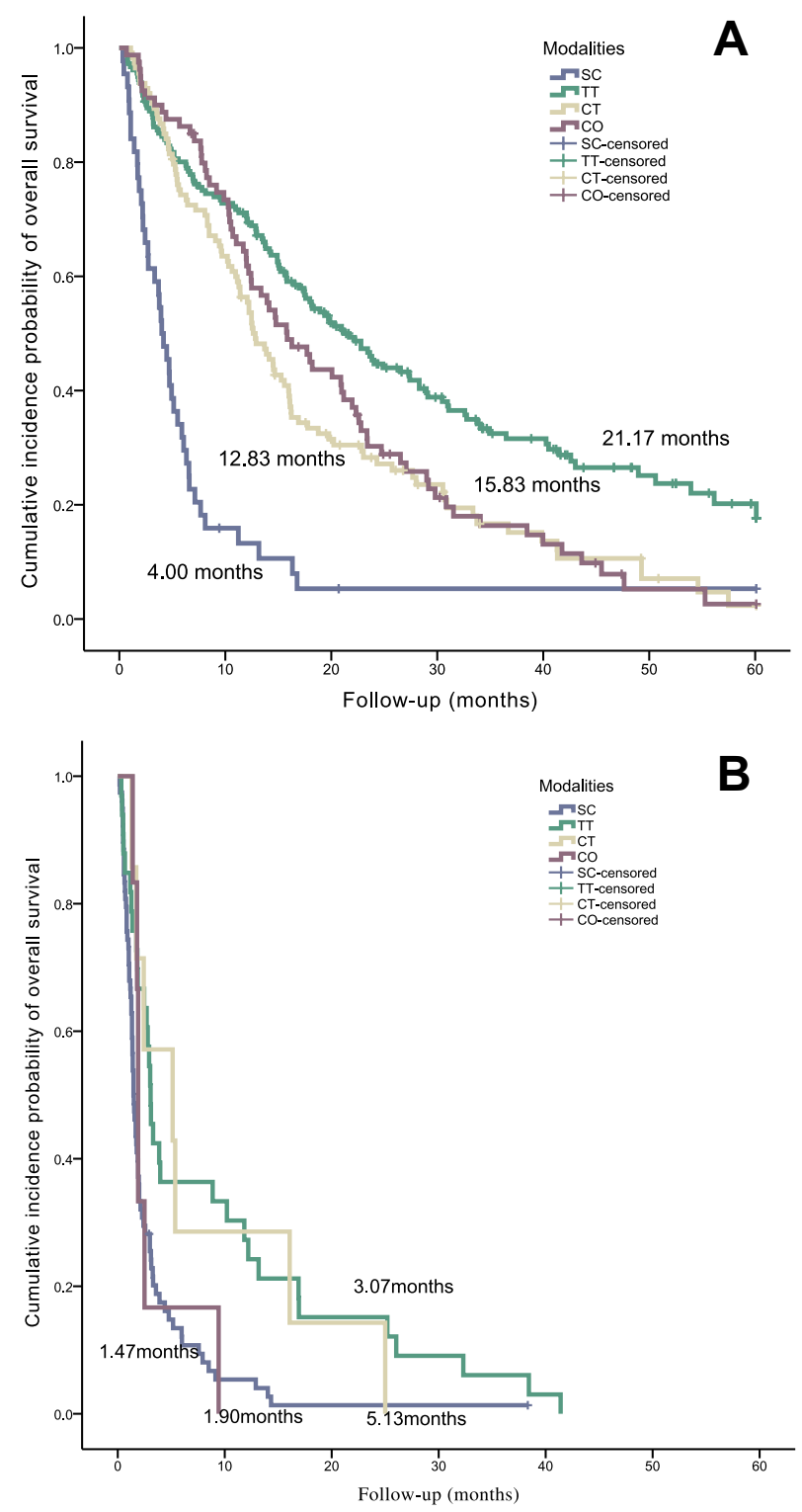

Figure I Kaplan-Meier censored cumulative survival curves for patients with supportive care (SC), targeted therapy (TT), chemotherapy (CT), and crossover (CO) treatments. (A) For 418 ECOG-PS 0-2 patients. (B) For I24 ECOG-PS 3-4 patients.

patients who received antineoplastic treatments had been assigned better ECOG-PS scores (0-2), and most of those receiving SC had been assigned poorer ECOG-PS scores (3-4). These findings suggest that most oncology specialists still considered objective criteria when recommending treatment for older patients with mNSCLC.

Based on our Cox regression analysis, older patients who had any of these antineoplastic treatments were less likely to have short OS than those receiving SC only. Previous studies have reported that carefully selected older patients receiving antineoplastic treatments are not more likely to have poorer PFS than younger patients. ${ }^{21,22}$
Our study has also found that antineoplastic treatments improved OS in older mNSCLC patients.

Patients at significantly increased risk of short OS were those aged $\geq 85$ years and those assigned poorer ECOP-PS scores (3-4). One study found that older cancer patients in 1994 were no less willing to receive antineoplastic treatment than young people. ${ }^{23}$ Because of advances in healthcare technology, many older people remain in good physical shape making them more open to receiving antineoplastic treatments. However, the benefit of antineoplastic treatments for OS remains limited for people age $\geq 85$ years because of the natural limitation of human life. In addition, age-related organ function decline and comorbid conditions can also make them more susceptible to the side effects associated with their medications. Treatment for these 2 groups of patients should focus on symptom control and quality of life rather than the length of OS only.

We found that patients with ECOG-PS scores of 0-2 who accepted TT alone had significantly better OS than those accepting $\mathrm{CT}$ alone or those accepting $\mathrm{CO}$ treatments. The side effects of chemotherapy include faster deterioration of performance status, malnutrition due to poor appetite, and fatal septicemia due to severe post-treatment leukopenia. These side effects harm the quality of life and limit daily activities. ${ }^{24}$ Hence, patients receiving treatments including CT did not have the best outcomes in our study. Targeted therapy has been applied to the treatment of mNSCLC for about two decades. TT makes use of pharmacological agents that inhibit cancer cell growth, increase cell death, and restrict the spread of cancer. Because it usually interferes with specific proteins involved in tumor genesis only, it does not have as many severe side effects as conventional chemotherapy. ${ }^{25-27}$ Older patients receiving TT are better able to maintain their usual daily activities because it slows down the deterioration of health and frailty and improves their quality of life, meaning they probably retain their autonomy. ${ }^{28}$

There are various targeted therapy agents available for the treatment of mNSCLC. ${ }^{28-30}$ Since 2011, Taiwan's National Health Insurance has approved targeted therapy drugs as the first-line antineoplastic treatment agents for locally advanced or metastatic pulmonary adenocarcinoma patients with epidermal growth factor receptor tyrosine kinase gene mutation and pulmonary adenocarcinoma patients who have a poor response to platinum-based chemotherapy. For older advanced NSCLC patients, it is recommended that specifically targeted drugs be routinely matched with an identified driver mutation because it not only improves treatment outcome and quality of life but also prevents unnecessary expenditures. ${ }^{30-33}$ 

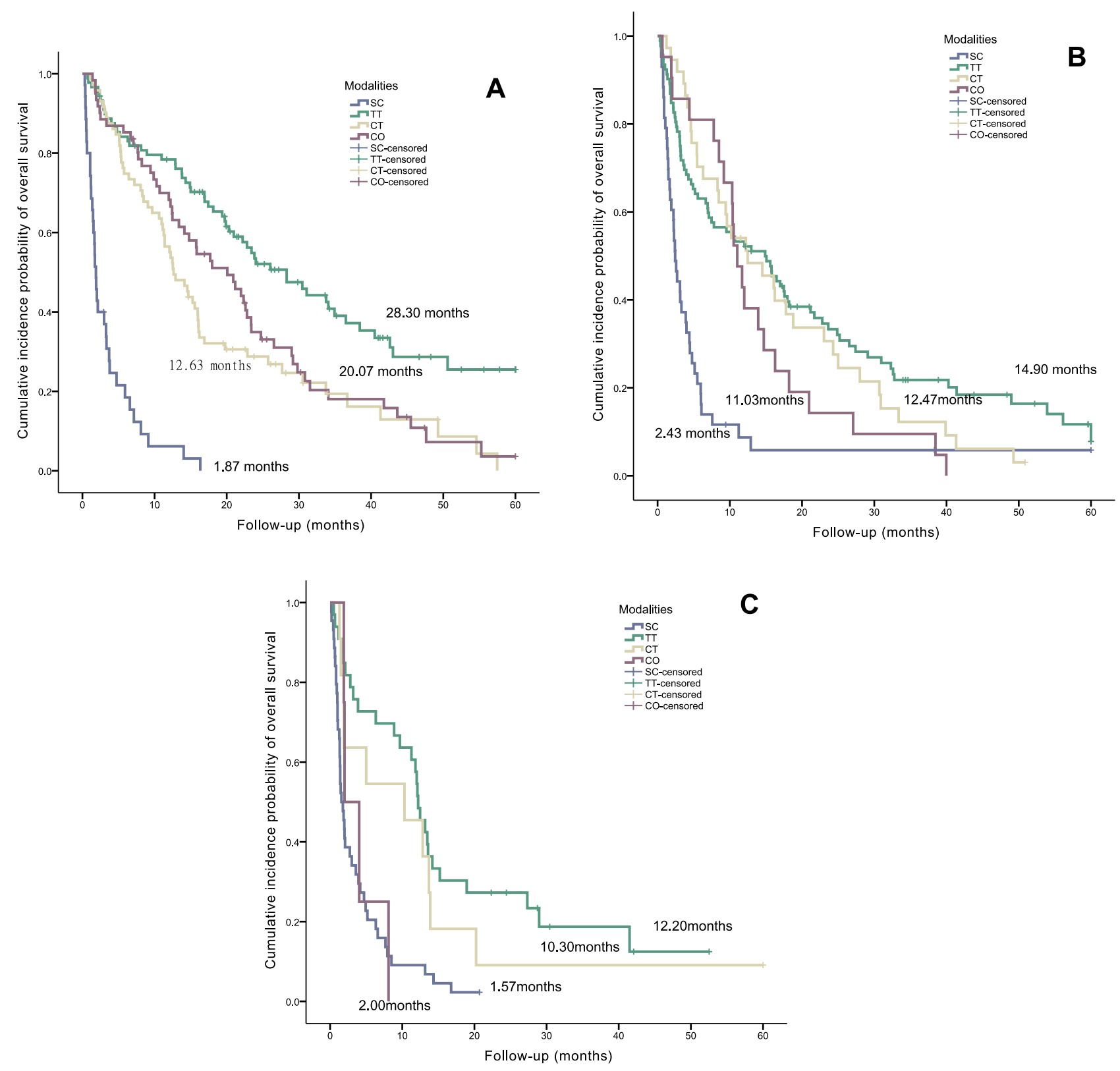

Figure 2 Kaplan-Meier censored cumulative survival curves for patients with supportive care (SC), targeted therapy (TT), chemotherapy (CT), and crossover (CO) treatments. (A) For 257 age 65-74 years old patients. (B) For 193 age 75-84 years old patients. (C) For 92 age $\geq 85$ years old patients.

Early palliative care for mNSCLC patients can prolong survival, improve their quality of life, and reduce psychological and spiritual distress compared to standard oncologic treatment. ${ }^{34,35}$ For patients with mNSCLC, palliative care and antineoplastic treatment are not mutually exclusive options. For older mNSCLC patients, whether they receive antineoplastic treatment or not, early palliative care may help them and their families understand prognosis, cope with distress, and assist in the medical decision and advance care planning. ${ }^{36-38}$ It should be integrated as part of the treatment plan.
The performance status of older patients is one of the most important factors affecting cancer treatment. It affects the choice of antineoplastic modalities and prognosis. ECOG-PS and Karnofsky scale are the most commonly used tools to assess the physical status of patients because they are easy to use and simple to understand. Most clinical guidelines recommend that patients with ECOG-PS $\leq 2$ undergo antineoplastic treatment to obtain better results. However, studies have pointed out that traditional physical status assessment tools cannot effectively predict the risks of antineoplastic treatment in older 
patients. $^{25,39}$ More comprehensive geriatric assessment tools of daily activities and cognitive function may also be added to the evaluation of patients because this might help patients, family, and oncologists make better antineoplastic treatment plans.

\section{Acknowledgments}

The authors would like to thank Kaohsiung Veterans General Hospital for providing data from its cancer registry database and for financial support, grant number VGHKS105-027.

\section{Disclosure}

The authors report no conflicts of interest for this work.

\section{References}

1. Yancik R, Ries LA. Cancer in older persons: an international issue in an aging world. Semin Oncol. 2004;31:128-136. doi:10.1053/j. seminoncol.2003.12.024

2. Howlader N, Krapcho M, Miller D, et al. SEER Cancer Statistics Review, 1975-2016. Bethesda M, ed. Vol. 2020. J Natl Cancer Inst; 2019

3. Siegel RL, Miller KD, Jemal A. Cancer statistics, 2020. CA Cancer $J$ Clin. 2020;70:7-30. doi:10.3322/caac.21590

4. Ministry of health and welfare. 2018 causes of death of Taiwan people; 2019. Available from: https://www.mohw.gov.tw/lp-4964-2. html. Accessed September 30, 2020.

5. Sung MR, Patel MV, Djalalov S, et al. Evolution of symptom burden of advanced lung cancer over a decade. Clin Lung Cancer. 2017;18 (274-280):e276. doi:10.1016/j.cllc.2016.12.010

6. Mosher CE, Champion VL, Azzoli CG, et al. Economic and social changes among distressed family caregivers of lung cancer patients. Support Care Cancer. 2013;21:819-826.

7. Weeks JC, Catalano PJ, Cronin A, et al. Patients' expectations about effects of chemotherapy for advanced cancer. $N$ Engl $J$ Med. 2012;367:1616-1625. doi:10.1056/NEJMoa1204410

8. Loerzel V. Cognitive representation of treatment-related symptoms in older adults with cancer. Cancer Nurs. 2017;40:230-236. doi:10.1097/NCC.0000000000000395

9. Sehl M, Sawhney R, Naeim A. Physiologic aspects of aging: impact on cancer management and decision making, part II. Cancer J. 2005;11:461-473. doi:10.1097/00130404-200511000-00005

10. Tan JY, Molassiotis A, Lloyd-Williams M, Yorke J. Burden, emotional distress and quality of life among informal caregivers of lung cancer patients: an exploratory study. Eur J Cancer Care. 2018;27.1: e12691. doi:10.1111/ecc.12691

11. Papastavrou E, Charalambous A, Tsangari H, Karayiannis G. The burdensome and depressive experience of caring: what cancer, schizophrenia, and Alzheimer's disease caregivers have in common. Cancer Nurs. 2012;35:187-194. doi:10.1097/NCC.0b013e31822cb4a0

12. Liu CY, Chen WT, Kung PT, et al. Characteristics, survival, and related factors of newly diagnosed colorectal cancer patients refusing cancer treatments under a universal health insurance program. $B M C$ Cancer. 2014;14:446. doi:10.1186/1471-2407-14-446

13. Yuan M, Huang -L-L, Chen J-H, Wu J, Xu Q. The emerging treatment landscape of targeted therapy in non-small-cell lung cancer. Signal Transduct Target Ther. 2019;4:61. doi:10.1038/s41392-019-0099-9

14. Sgambato A, Casaluce F, Maione P, et al. The role of EGFR tyrosine kinase inhibitors in the first-line treatment of advanced non small cell lung cancer patients harboring EGFR mutation. Curr Med Chem. 2012;19:3337-3352. doi:10.2174/092986712801215973
15. Taiwan cancer register. Introduction of Taiwan cancer registry: taiwan cancer register. Available from: http://cr.cph.ntu.edu.tw/main. php?Page=N1. Accessed February 20, 2020.

16. Hurria A, Levit LA, Dale W, et al. Improving the evidence base for treating older adults with cancer: American Society of Clinical Oncology statement. J Clin Oncol. 2015;33:3826-3833. doi:10. 1200/JCO.2015.63.0319

17. Kim C, Liu SV. First-line EGFR TKI therapy in non-small-cell lung cancer: looking back before leaping forward. Ann Oncol. 2019;30:1852-1855.

18. Bradley CJ, Yabroff KR, Mariotto AB, Zeruto C, Tran Q, Warren JL. Antineoplastic treatment of advanced-stage non-small-cell lung cancer: treatment, survival, and spending (2000 to 2011). J Clin Oncol. 2017;35:529-535. doi:10.1200/JCO.2016.69.4166

19. PresleyCJ, ReynoldsCH, Langer CJ. Caring for the older population with advanced lung cancer. In: Dizon DS, Pennel N, Rugo HS, et al, editors. American Society of Clinical Oncology Educational Book [Internet]. American Society of Clinical Oncology; 2017:587-596. Available from: https://ascopubs.org/doi/abs/10.1200/EDBK_179850. Accessed February 20, 2020.

20. National health insurance administration. Patients with catastrophic illnesses or rare diseases; 2016. Available from: https://www.nhi.gov. tw/English/Content_List.aspx ?n=F5B8E49CB4548C60\&topn= 1D1ECC54F86E9050. Accessed February 20, 2020.

21. Kumar A, Soares HP, Balducci L, Djulbegovic B; National Cancer I. Treatment tolerance and efficacy in geriatric oncology: a systematic review of phase III randomized trials conducted by five National Cancer Institute-sponsored cooperative groups. J Clin Oncol. 2007;25:1272-1276. doi:10.1200/JCO.2006.09.2759

22. Batum O, Anar C, Ozdogan Y, Ermin S, Yilmaz U. Use of adjuvant chemotherapy for nonsmall cell lung cancer: is advanced age a prognostic factor? Indian J Cancer. 2018;55:282-287. doi:10. 4103/ijc.IJC_27_18

23. Yellen SB, Cella DF, Leslie WT. Age and clinical decision making in oncology patients. J Natl Cancer Inst. 1994;86:1766-1770. doi:10. 1093/jnci/86.23.1766

24. Karczmarek-Borowska B, Pelc M, Rabiej E, Gradalska-Lampart M. The quality of life of non-small cell lung cancer patients treated with chemotherapy. Pneumonol Alergol Pol. 2014;82:349-357. doi:10.5603/PiAP.2014.0044

25. Pal SK, Figlin RA, Reckamp K. Targeted therapies for non-small cell lung cancer: an evolving landscape. Mol Cancer Ther. 2010;9:1931-1944. doi:10.1158/1535-7163.MCT-10-0239

26. Larsen JE, Cascone T, Gerber DE, Heymach JV, Minna JD. Targeted therapies for lung cancer: clinical experience and novel agents. Cancer J. 2011;17:512-527. doi:10.1097/PPO.0b013e3 $1823 \mathrm{e} 701 \mathrm{a}$

27. Sim EH, Yang IA, Wood-Baker R, Bowman RV, Fong KM. Gefitinib for advanced non-small cell lung cancer. Cochrane Database Syst Rev. 2018;1:CD006847.

28. Daste A, Chakiba C, Domblides C, et al. Targeted therapy and elderly people: a review. Eur J Cancer. 2016;69:199-215. doi:10.1016/j. ejca.2016.10.005

29. Kalia M. Biomarkers for personalized oncology: recent advances and future challenges. Metabolism. 2015;64:S16-S21. doi:10.1016/j. metabol.2014.10.027

30. Barlesi F, Mazieres J, Merlio JP, et al. Routine molecular profiling of patients with advanced non-small-cell lung cancer: results of a 1-year nationwide programme of the French Cooperative Thoracic Intergroup (IFCT). Lancet. 2016;387:1415-1426. doi:10.1016/ S0140-6736(16)00004-0

31. Kris MG, Johnson BE, Berry LD, et al. Using multiplexed assays of oncogenic drivers in lung cancers to select targeted drugs. JAMA. 2014;311:1998-2006. doi:10.1001/jama.2014.3741

32. Puri T. Targeted therapy in nonsmall cell lung cancer. Indian J Cancer. 2017;54:83-88. doi:10.4103/ijc.IJC_258_17 
33. Albaba H, Lim C, Leighl NB. Economic considerations in the use of novel targeted therapies for lung cancer: review of current literature. Pharmacoeconomics. 2017;35:1195-1209. doi:10.1007/s40273-0170563-8

34. Ambroggi M, Biasini C, Toscani I, et al. Can early palliative care with anticancer treatment improve overall survival and patient-related outcomes in advanced lung cancer patients? A review of the literature. Support Care Cancer. 2018;26(9):2945-2953. doi:10. 1007/s00520-018-4184-3

35. Temel JS, Greer JA, Muzikansky A, et al. Early palliative care for patients with metastatic non-small-cell lung cancer. $N$ Engl J Med. 2010;363(8):733-742. doi:10.1056/NEJMoa1000678

36. Greer JA, Pirl WF, Jackson VA, et al. Effect of early palliative care on chemotherapy use and end-of-life care in patients with metastatic non-small-cell lung cancer. J Clin Oncol. 2012;30(4):394-400. doi:10.1200/JCO.2011.35.7996
37. Yoong J, Park ER, Greer JA, et al. Early palliative care in advanced lung cancer: a qualitative study. JAMA Intern Med. 2013;173 (4):283-290. doi:10.1001/jamainternmed.2013.1874

38. Lammers A, Slatore CG, Fromme EK, et al. Association of early palliative care with chemotherapy intensity in patients with advanced stage lung cancer: a national cohort study. J Thorac Oncol. 2019;14 (2):176-183. doi:10.1016/j.jtho.2018.09.029

39. Mohile SG, Dale W, Somerfield MR, Hurria A. Practical assessment and management of vulnerabilities in older patients receiving chemotherapy: ASCO Guideline for Geriatric Oncology Summary. J Oncol Pract. 2018;14(7):442-446. doi:10.1200/JOP.18.00180

\section{Publish your work in this journal}

Cancer Management and Research is an international, peer-reviewed open access journal focusing on cancer research and the optimal use of preventative and integrated treatment interventions to achieve improved outcomes, enhanced survival and quality of life for the cancer patient.
The manuscript management system is completely online and includes a very quick and fair peer-review system, which is all easy to use. Visit http://www.dovepress.com/testimonials.php to read real quotes from published authors. 